\title{
Aspecto macroscópico del infarto de miocardio secundario a hipotensión arterial
} Gross appearance of myocardial infarction due to arterial hypotension

\author{
Dr. César Augusto Durán López ${ }^{1}$
}

https://doi.org/10.5377/rcfh.v5i2.8900

${ }^{1}$ Departamento de Patología, Universidad Nacional Autónoma de Honduras.

Correspondencia a:cesar.duran@unah.edu.hn Recibido: 18 de agosto 2019 Aceptado: 26 de septiembre 2019

Citar como: Durán-López CA. Aspecto macroscópico del infarto de miocardio secundario a hipotensión arterial. Rev. Cienc. Forenses Honduras, 2019; 5(2) 35.

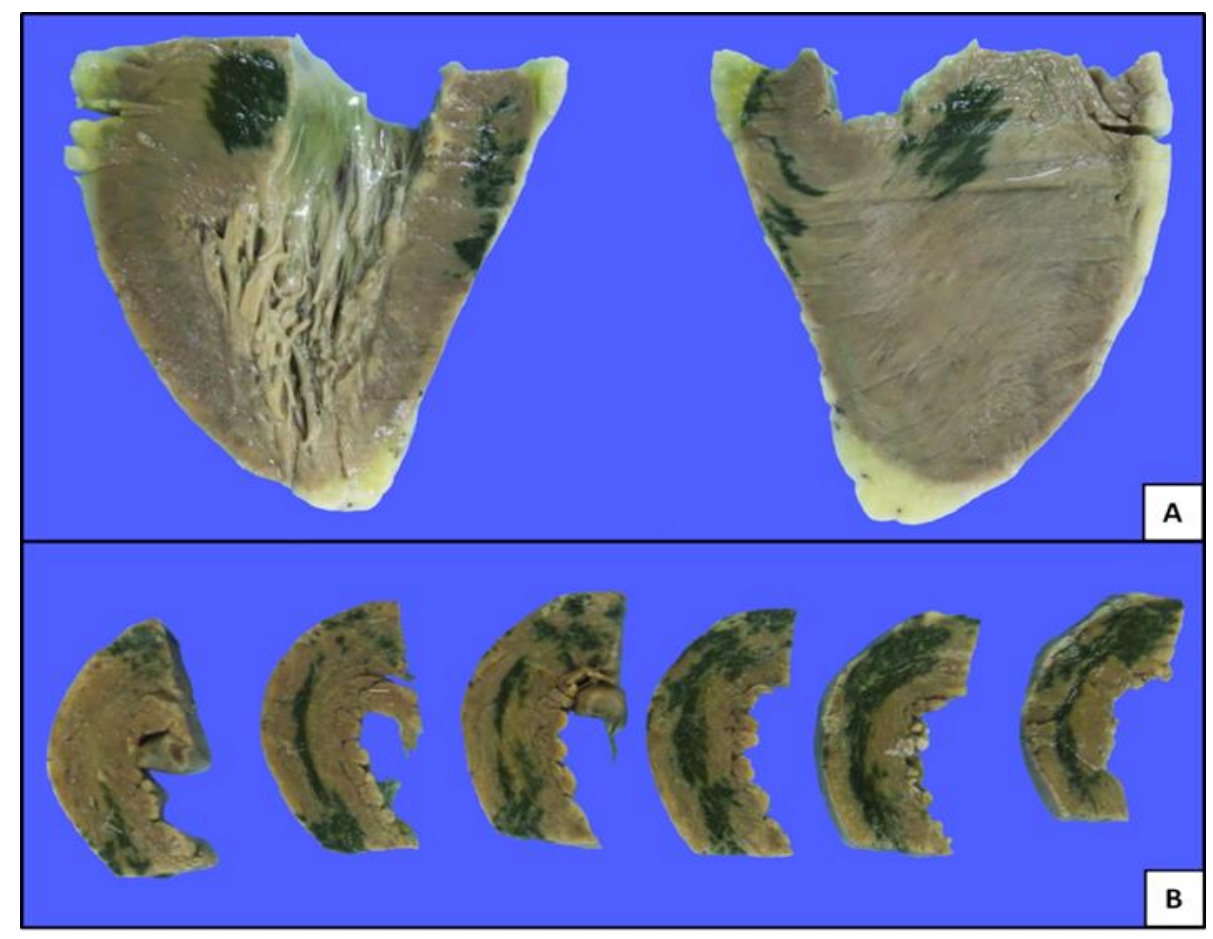

Femenina de 30 años, obesa, epiléptica, que ingresó al hospital hipotensa (80/40 mm Hg), tenía ictericia, acolia y coluria de seis días, también hubo fiebre y alteraciones de la conciencia de 24 horas, falleció al tercer día de hospitalización. En la autopsia se encontró cirrosis micronodular, ascitis serosa $(4,600 \mathrm{cc})$, esplenomegalia (350 g), bronconeumonía derecha e infarto de miocardio reciente. La causa de muerte fue choque séptico. El infarto por hipoperfusión contribuyó al deceso exacerbando la disfunción miocárdica.

En la Figura A se observa el ventrículo izquierdo, a la derecha el corte a nivel del septum, a la izquierda la luz ventricular. La Figura B muestra cortes trasversales de la circunferencia ventricular. Las áreas verdosas irregulares en todos los cortes corresponden a zonas de infarto reciente. La coloración verdosa se debe a la pigmentación por bilirrubina durante la fijación. El patrón circunferencial del infarto de miocardio es producto de la hipotensión al disminuir la perfusión global del corazón ${ }^{1}$. 